compounds could have been important for kicking off the chemistry that led to life on Earth, the researchers say.

Astrophys. J. Lett. 792, L2 (2014)

\section{MICROBIOLOGY}

\section{How Salmonella bounces back}

Two groups have shown how Salmonella bacteria can resist antibiotics.

Dirk Bumann of the University of Basel in Switzerland and his colleagues infected mice with modified Salmonella strains that glow green when they divide. They found varying rates of division in different tissues, and most of the bacteria that survived antibiotic treatment had a moderate growth rate.

In a separate study, Médéric Diard at the Swiss Federal Institute of Technology in Zurich and his co-workers found that whereas antibiotics kill off less-dangerous Salmonella mutants in the mouse gut cavity, the morevirulent strains escape by hiding inside the gut tissue. After antibiotic treatment ended, the more-virulent bacteria repopulated the gut.

The findings could point to new strategies for antibiotic treatment, the authors say. Cell 158, 722-733 (2014); Curr. Biol. http://doi.org/t7z (2014)

\section{ASTRONOMY}

\section{Dusty visitors from interstellar space}

Seven particles captured by NASA's Stardust spacecraft may be the first sample of dust from beyond the Solar System that has been brought back to Earth.

Andrew Westphal at the University of California, Berkeley, and his colleagues with the help of 30,714 citizen scientists around the world scanned more than 1 million images of tracks left by particles on Stardust's collectors. They identified seven candidates with a surprising variety of crystal structures and elemental compositions.
These particles could help to explain the origin and evolution of interstellar dust, which current astronomical observations can only guess at. Science 345, 786-791 (2014)

\section{CONSERVATION BIOLOGY}

\section{Poaching leads to elephant decline}

The illegal killing of elephants in Africa to supply the ivory trade has reached unsustainable rates.

George Wittemyer at Colorado State University in Fort Collins and his colleagues used data from elephant carcass surveys in 45 sites across Africa to model broader trends in elephant poaching on the continent. They found that levels of illegal killing peaked in 2011 at $8 \%$ of the global population, leading to the loss of roughly 40,000 elephants, or a $3 \%$ overall reduction in animal numbers that year.

Decreasing demand for ivory in China is key to conserving elephants, say the authors.

Proc. Natl Acad. Sci. USA

http://dx.doi.org/10.1073/

pnas.1403984111 (2014)

\section{Secret to Ebola's success}

The Ebola virus might elude immune responses by stopping a key protein in infected cells from activating defence genes.

Ebola, which kills up to $90 \%$ of people it infects, is known to disrupt the activity of interferon, a crucial antiviral protein. Gaya Amarasinghe at Washington University School of Medicine in St Louis, Missouri, and his colleagues found that an Ebola viral protein blocks the transport of an interferon-activated protein called STAT 1 into the cell nucleus. STAT1 is needed in the nucleus to stimulate defence mechanisms.

The results suggest new drug targets in the ongoing fight against the virus.

Cell Host Microbe 16, 187-200 (2014)

\title{
SOCIAL SELECTION Romilumatices
}

\section{Strong words over a 'Hobbit'}

Two papers stirred up the palaeoanthropology world by suggesting that Homo floresiensis - a putative human relative discovered on the Indonesian island of Flores in 2003 - was instead an example of Homo sapiens with Down's syndrome. The theory, in the Proceedings of the National Academy of Sciences, was greeted with much scepticism. As part of a string of tweets, anthropologist Holly Dunsworth at the University of Rhode Island in Kingston said: "Conclusion [is] based seemingly on zilch." Co-author Robert Eckhardt, a geneticist at Pennsylvania State University, defended the diagnosis in a comment posted on a blog of the Natural History Museum in London, saying that his group and others have spent the past decade "trying to turn the "Hobbit' circus into science".

Proc. Natl Acad. Sci. USA http://doi.org/t66; http://doi.org/t65 (2014)

\begin{tabular}{l|l}
\hline Based on data from altmetric.com. & DNATURE.COM \\
$\begin{array}{l}\text { Altmetric is supported by Macmillan } \\
\text { Science and Education, which owns } \\
\text { Nature Publishing Group. }\end{array}$ & $\begin{array}{l}\text { For more on } \\
\text { popular papers: } \\
\text { g0.nature.com/qizfui }\end{array}$ \\
\hline
\end{tabular}

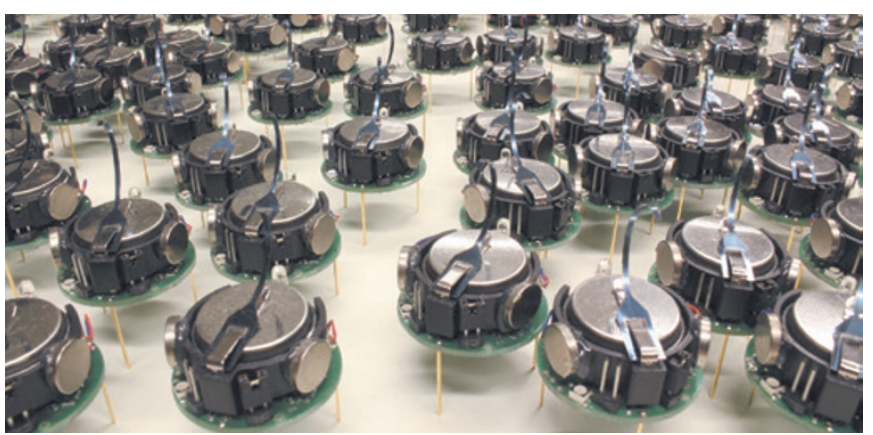

\section{ENGINEERING \\ Robot swarms take shape}

A thousand-strong army of coin-sized robots (pictured) can arrange itself into various configurations.

Michael Rubenstein and his co-workers at Harvard University in Cambridge, Massachusetts, programmed 1,024 robots with a simple set of rules and an image of a shape to be formed. Four 'seed robots' act as a point of origin for a coordinate system and send their coordinates to neighbours using infrared light. This information spreads through the group, allowing each robot to determine its relative location in the swarm.
The robot flock can form programmed shapes - such as the letter ' $\mathrm{K}$ ' - in around 12 hours and is the largest yet to demonstrate collective behaviour, the authors say. Science 345, 795-799 (2014)

\section{CLARIFICATION \\ The Research Highlight \\ 'Brain scans predict TV hits' (Nature 512,$8 ; 2014$ ) notes that Jacek Dmochowski is at Stanford University; however, the research described was done at the City College of New York.}

\section{$\rightarrow$ NATURE.COM}

For the latest research published by Naturevisit:

www.nature.com/latestresearch 